\title{
Genetics and the Gynecologic Patient
}

\author{
Katrina S. Wade, MD, Jacob M. Estes, MD, Richard C. Kline, MD \\ Department of Gynecologic Oncology, Ochsner Clinic Foundation, New Orleans, LA
}

Background: The field of hereditary cancer syndromes and genetic testing for patients and families is a rapidly evolving discipline, with an emphasis on cancer prevention.

Methods: We review the literature regarding the most common genetic syndromes associated with gynecologic malignancies and discuss the management of these conditions. We also examine the logistic process surrounding cancer genetic testing and identify some perceived barriers.

Results: Five genetic syndromes are known to be associated with gynecologic malignancies: hereditary breast and ovarian cancer, Lynch, Cowden, Peutz-Jeghers, and Li-Fraumeni. Each is associated with varying risks of breast, ovarian, and uterine malignancies. The National Comprehensive Cancer Network guidelines regarding the management of these syndromes are focused primarily on reducing the risk of developing gynecologic malignancies. However, great complexity is involved with genetic testing for patients and their families, and barriers exist for the widespread use and implementation of such testing.

Conclusion: Genetic testing is fundamental to primary cancer prevention and to oncologic care. Physicians, payers, and institutions must work collaboratively to maximize genetic testing with the goals of primary cancer prevention and treatment.

Keywords: Cowden syndrome, genes-BRCA1, genes-BRCA2, genital neoplasms-female, genetic diseases-inborn, genetic testing, hereditary breast and ovarian cancer syndrome, Li-Fraumeni syndrome, Lynch syndrome, Peutz-Jeghers syndrome

Address correspondence to Katrina S. Wade, MD, Department of Gynecologic Oncology, Ochsner Clinic Foundation, 1514 Jefferson Hwy., New Orleans, LA 70121. Tel: (504) 842-4165. Email: katrina.wade@ochsner.org

\section{INTRODUCTION}

In 2015, President Barack Obama executed an initiative that encouraged the development of precision medicine in all disease sites. Precision medicine is medical care designed to optimize therapeutic benefit for particular groups of patients, especially by using genetic or molecular profiling. One of the models for precision medicine in the field of gynecologic oncology is the genetic predisposition to gynecologic cancers, the most common of which are hereditary breast and ovarian cancer syndrome and Lynch syndrome. ${ }^{1,2}$ Although a high-risk cancer susceptibility mutation is ideally identified before cancer is diagnosed, identifying a mutation in women with cancer helps with tumor biology, prognosis, treatment decisions, clinical trial enrollment, risk assessment and prevention of subsequent malignancies, and cancer risk and prevention for blood relatives. Historically, changes to cancer management based on genetic testing results were lacking. However, beginning in 2014, the US Food and Drug Administration has approved some treatments, including poly (adenosine diphosphate-ribose) polymerase (PARP) inhibitors for the treatment of women with BRCA-mutated ovarian cancer and immunotherapy for endometrial cancers with microsatellite instability consistent with Lynch syndrome. . $^{3-8}$

In this article, we review the 5 genetic syndromes associated with gynecologic malignancies and their management.
We also highlight some of the logistics surrounding the evolving subject of cancer genetic testing.

\section{GENETIC SYNDROMES IN GYNECOLOGIC CANCER} Hereditary Breast and Ovarian Cancer Syndrome

Approximately $15 \%$ to $20 \%$ of patients with ovarian cancer are BRCA1 or BRCA2 mutation carriers. ${ }^{9}$ These mutations increase a woman's lifetime risk of ovarian cancer up to $40 \%$ for BRCA1 carriers and up to $20 \%$ for BRCA2 carriers. ${ }^{9,10}$ Estimates of the lifetime risk of breast cancer for BRCA1/2 mutation carriers range from $41 \%$ to $90 \%$. In a sample of 488 women with nonmetastatic breast cancer, $6.1 \%$ had a BRCA1/2 mutation, but mutation prevalence decreased with age (12\% in women diagnosed at 45 years of age or younger and $3 \%$ in women diagnosed at 46 years of age or older). ${ }^{11}$ Other genes in the homologous recombination pathway, such as RAD51C, RAD51D, BRIP1, PALB2, and BARD1, may also influence breast and ovarian cancer risk and biology. ${ }^{12-14}$ Patients with an increased likelihood of having inherited a predisposition to breast and ovarian cancer should receive genetic counseling and be offered genetic testing (Table 1). ${ }^{15}$

Recommendations for the medical management of hereditary breast and ovarian cancer are based on an appreciation of the increased risk for cancer and the early onset of 
Table 1. Consensus Recommendations for Genetic Counseling and Testing for Hereditary Breast and Ovarian Cancer ${ }^{15}$

\begin{tabular}{|c|c|}
\hline Women AFFECTED With the Following Cancers & $\begin{array}{l}\text { Women UNAFFECTED With Cancer but With } \\
\text { Relatives Meeting the Following Criteria }\end{array}$ \\
\hline $\begin{array}{l}\text { High-grade epithelial ovarian/tubal/peritoneal cancer } \\
\text { Breast cancer diagnosed at } \leq 45 \text { years } \\
\text { Breast cancer and close relative with breast cancer diagnosed at } \leq 50 \text { years or } \\
\text { close relative with epithelial ovarian/tubal/peritoneal cancer at any age } \\
\text { Breast cancer diagnosed at } \leq 50 \text { years and a limited family history } \\
\text { Breast cancer and } \geq 2 \text { close relatives with breast cancer at any age } \\
\text { Breast cancer and } \geq 2 \text { close relatives with pancreatic cancer or aggressive } \\
\text { prostate cancer (Gleason score } \geq 7 \text { ) } \\
\text { Two breast primaries, with the first diagnosed at }<50 \text { years } \\
\text { Triple-negative breast cancer diagnosed at } \leq 60 \text { years } \\
\text { Breast cancer and Ashkenazi Jewish ancestry } \\
\text { Pancreatic cancer and } \geq 2 \text { close relatives with breast, } \\
\text { ovarian/tubal/peritoneal, pancreatic, or aggressive prostate cancer } \\
\text { (Gleason score } \geq 7 \text { ) }\end{array}$ & $\begin{array}{l}\text { First degree or several close relatives who meet } \\
\text { one of the criteria in the left column } \\
\text { Close relative carrying a known BRCA1 or BRCA2 } \\
\text { mutation } \\
\text { Close relative with male breast cancer }\end{array}$ \\
\hline
\end{tabular}

disease. For a woman who is a carrier of a BRCA1/2 mutation, the National Comprehensive Cancer Network (NCCN) guidelines suggest that training in breast awareness with monthly self-examinations should begin at 18 years of age, and semiannual clinical breast examinations should begin at 25 years of age. ${ }^{16}$ Patients between the ages of 25 and 29 years should receive annual breast magnetic resonance imaging (MRI) screenings. The age to begin screening can be individualized if the family history includes a breast cancer diagnosis prior to 30 years of age. Breast MRI screening is preferred to mammogram in the 25- to 29-year age group because of increased breast tissue density. For patients between 30 and 75 years of age, both annual mammogram and breast MRI should be done, alternating every 6 months. For patients older than 75 years, management should be considered on an individual basis.

Counseling for women with a confirmed BRCA1/2 mutation includes discussion of risk-reducing mastectomy and/or risk-reducing salpingo-oophorectomy. Risk-reducing salpingo-oophorectomy is the standard of care for ovarian cancer risk management in BRCA1/2 carriers. For women who do not elect risk-reducing salpingo-oophorectomy, screening with transvaginal ultrasound (TVUS) and the cancer antigen 125 (CA-125) test can be considered every 6 months. However, providers should acknowledge the lack of high-quality data to inform these recommendations, and some patients may reasonably prefer not to undergo screening. In a cohort of 888 women carriers of BRCA1 or BRCA2 mutations who underwent screening with annual TVUS and CA-125, 5 of 10 cancers were diagnosed in women who had had normal screening results 3 to 10 months previously. Eight of the 10 cancers were stage III at diagnosis. ${ }^{17}$

\section{Lynch Syndrome}

Lynch syndrome, also known as hereditary nonpolyposis colorectal cancer, is caused by mutations in DNA mismatch repair (MLH1, MSH2, MSH6, PMS2). Women with Lynch syndrome have increased risk for endometrial and ovarian cancers. The lifetime risks are $20 \%$ to $71 \%$ and $0 \%$ to $13.5 \%$ for endometrial and ovarian cancer, respectively. ${ }^{18}$ Women with Lynch syndrome also have a $25 \%$ to $50 \%$ life- time risk of colorectal cancer, a somewhat lower risk than their male counterparts. ${ }^{19}$ Other cancer risks include pancreatic, central nervous system, and urothelial malignancies. Patients with an increased likelihood of having Lynch syndrome should receive genetic counseling and be offered genetic testing (Table 2). ${ }^{15}$

The NCCN guidelines suggest that carriers of MLH1, $\mathrm{MSH}$ 2, MSH6, or PMS2 mutations consider total abdominal hysterectomy and/or bilateral salpingo-oophorectomy when childbearing is complete. ${ }^{16}$ No clear evidence supports routine screening for gynecologic cancers in these carriers. Annual endometrial sampling can be considered beginning at 30 to 35 years of age. ${ }^{20}$ Routine TVUS and CA- 125 screening is not typically recommended because these screening tests have not been shown to be sufficiently sensitive or specific. ${ }^{21}$ Colonoscopy should be performed every 1 to 2 years starting at age 20 to 25 years or 2 to 5 years prior to the earliest familial cancer diagnosis. Additional cancer screening can be considered based on the specific gene mutation.

\section{Cowden Syndrome}

Cowden syndrome results from a pathogenic mutation in PTEN. The syndrome is associated with multiple hamartomas and/or cancerous lesions in various organs and

Table 2. Consensus Recommendations for Genetic Counseling and Testing for Lynch Syndrome ${ }^{15}$

\section{Patients With the Following}

Endometrial or colorectal cancer with evidence of microsatellite instability or loss of a DNA mismatch repair protein (MLH1, MSH2, MSH6, PMS2) on immunohistochemistry

First-degree relative affected with endometrial or colorectal cancer who was either diagnosed at $<60$ years or who is identified to be at risk for Lynch syndrome by a systematic clinical screen that incorporates a focused personal and medical history

First- or second-degree relative with a known mutation in a mismatch repair gene 
Table 3. Consensus Recommendations for Genetic Counseling and Testing for Cowden Syndrome ${ }^{26}$

\begin{tabular}{ll}
\hline \multicolumn{1}{c}{ Major Criteria } & Minor Criteria \\
\hline Breast cancer & Autism spectrum disorder \\
Endometrial cancer & Colon cancer \\
Follicular thyroid cancer & Esophageal glycogenic acanthoses \\
Multiple gastrointestinal hamartomas or ganglioneuromas & Lipomas \\
Macrocephaly & Intellectual disability \\
Mucocutaneous lesions & Thyroid adenomas, goiter, nodules \\
Multiple trichilemmomas & Papillary or follicular thyroid caner \\
Multiple acral/palmoplantar keratosis, pits, papules & Renal cell carcinoma \\
Mucocutaneous neuromas & Single gastrointestinal hamartoma or ganglioneuroma \\
Multifocal oral mucosal papillomatosis & Vascular anomalies \\
Multiple cutaneous facial papules (verrucous) & \\
\hline
\end{tabular}

tissues, including the skin, mucous membranes, breast, thyroid, endometrium, and brain. ${ }^{22,23}$ The lifetime risk for breast cancer for women diagnosed with Cowden syndrome has been estimated at $25 \%$ to $50 \%$, with an average age of 38 to 50 years at diagnosis. ${ }^{22,23}$ Thyroid disease, including benign multinodular goiter, adenomatous nodules, and follicular adenomas, has been reported to occur in approximately $30 \%$ to $68 \%$ of adults with PTEN mutations, ${ }^{24}$ and the lifetime risk for thyroid cancer has been estimated at 3\% to $10 \% .{ }^{22}$ Macrocephaly and autism spectrum disorders are strongly associated with Cowden syndrome. ${ }^{25}$ Patients with an increased likelihood of having Cowden syndrome should receive genetic counseling and be offered genetic testing (Table 3). ${ }^{26}$

The NCCN guidelines suggest that women with Cowden syndrome should focus on primary and secondary prevention options for breast cancer because, based on the available literature, breast cancer is the cancer most commonly associated with Cowden syndrome. ${ }^{16,22,23}$ Women with Cowden syndrome should begin regular monthly breast self-examinations at 18 years of age and have semiannual clinical breast examinations beginning at age 25 years. Women with Cowden syndrome should also have an annual mammogram and breast MRI with contrast screening starting at age 30 to 35 years. Risk-reducing mastectomy can be considered. The NCCN guidelines state that endometrial cancer screening does not have a proven benefit in women with Cowden syndrome; however, screening with endometrial biopsy every 1 to 2 years may be considered. ${ }^{16}$ Although no data support risk reduction surgery in women with Cowden syndrome, the option of risk-reducing hysterectomy should be considered. Oophorectomy is not indicated for women with Cowden syndrome alone because Cowden syndrome is not associated with an increased risk of ovarian cancer; however, oophorectomy may be indicated for other reasons.

\section{Peutz-Jeghers Syndrome}

Peutz-Jeghers syndrome is characterized by gastrointestinal polyps; mucocutaneous pigmentation; and elevated risk for gastrointestinal, breast, and nonepithelial ovarian cancers. The syndrome is associated with mutations in the STK11/LKB1 gene. The breast cancer risk in women with Peutz-Jeghers syndrome is $8 \%$ at 40 years of age, $13 \%$ at 50 years, $31 \%$ at 60 years, and $45 \%$ at 70 years. $^{27}$
Peutz-Jeghers syndrome is associated with an elevated risk of cervical cancer, most commonly adenoma malignum, with an estimated lifetime risk of $10 \%$ in addition to a lifetime risk of $21 \%$ for ovarian cancer, most commonly sex cordstromal tumors. ${ }^{28}$ A clinical diagnosis of Peutz-Jeghers syndrome can be made when an individual meets 2 or more of the following criteria ${ }^{29}$ : (1) 2 or more Peutz-Jeghers-type hamartomatous polyps of the small intestine; (2) mucocutaneous hyperpigmentation of the mouth, lips, nose, eyes, genitalia, or fingers; and (3) a family history of Peutz-Jeghers syndrome.

Women with Peutz-Jeghers syndrome are advised to undergo annual screening for cervical cancer (including Pap smear) starting at age 21 years. ${ }^{30}$ As with other hereditary syndromes, screening for ovarian cancer in women with Peutz-Jeghers syndrome is controversial, given the lack of proven benefit in reducing mortality from ovarian cancer. ${ }^{17}$ However, TVUS can be considered beginning at age 18 to 20 years. Monthly breast self-examinations for women with Peutz-Jeghers syndrome starting at age 18 years and annual breast MRI and/or mammography starting at age 25 years are suggested. ${ }^{30}$

\section{Li-Fraumeni Syndrome}

Li-Fraumeni syndrome is a rare hereditary cancer syndrome associated with TP53 mutations. Only approximately 300 families with Li-Fraumeni syndrome are listed in a registry maintained by the National Cancer Institute (NCl). ${ }^{31}$ Li-Fraumeni syndrome is associated with a high lifetime risk for cancer; an analysis from the $\mathrm{NCl}$ Li-Fraumeni Syndrome Study $(n=286)$ showed a cumulative lifetime cancer incidence of nearly $100 \% .^{32}$ Li-Fraumeni syndrome is characterized by a wide spectrum of neoplasms occurring at a young age, including soft tissue sarcomas, osteosarcomas, premenopausal breast cancer, colon cancer, gastric cancer, adrenocortical carcinoma, and brain tumors. ${ }^{33}$

Classic Li-Fraumeni syndrome diagnostic criteria, based on a study by $\mathrm{Li}$, Fraumeni, and colleagues involving 24 Li-Fraumeni syndrome kindreds, are the following ${ }^{33,34}$ : (1) a member of a kindred with a known TP53 mutation; (2) a combination of an individual diagnosed at 45 years of age or younger with a sarcoma and a first-degree relative diagnosed with cancer at 45 years of age or younger, and (3) an additional first- or second-degree relative in the same 
lineage with cancer diagnosed at younger than 45 years of age or a sarcoma diagnosed at any age.

The NCCN recommendations for breast cancer screening in patients with Li-Fraumeni syndrome are similar to those for BRCA-related breast and ovarian cancer syndrome management, although screening is recommended to begin at an earlier age. ${ }^{16}$ Annual breast MRI and mammography beginning at age 20 years (or at the age of earliest known breast cancer in the family if younger than 20 years) are recommended because of the very early age of onset of breast cancer in families with Li-Fraumeni syndrome.

\section{GENETIC TESTING How Genetic Testing Is Performed}

Genetic risk assessment starts with a detailed family history, even for patients who already meet testing criteria, because some women might be best served by testing for multiple genes or syndromes. Genetic testing requires informed consent that should include pretest education and counseling concerning the risks, benefits, and limitations of testing, including the implications of both positive and negative results. False negative results are a risk, and uncertainties are associated with genetic variants of unknown significance. Posttest counseling should include education on risk-reduction strategies. ${ }^{15}$

The family member affected with cancer has the highest likelihood of carrying the mutation and thus should be tested first whenever possible. If more than one family member is affected, members with the following factors should be considered for testing first: youngest age at diagnosis, bilateral disease or multiple primaries, and most closely related to the proband. Testing of unaffected individuals should only be considered when an appropriate family member is not available for testing (eg, the family member is deceased). Another important consideration is that family histories change over time and should be reassessed regularly. For example, patients and family members may have had a hysterectomy and/or ovarian removal which may mask the number of cancers identified in a family.

Genetic assessment for Lynch syndrome, in contrast to BRCA1/2 mutation, may be performed first through tumor testing. Immunohistochemistry for the 4 most common mismatch repair proteins is inexpensive and available through most pathology laboratories. Loss of mismatch repair proteins can direct targeted germline genetic testing. The distinction between germline testing and tumor, or somatic, testing is noteworthy. Germline mutations are present in germ cells at conception and can be inherited by future generations, in contrast to somatic mutations that occur after fertilization and are only perpetuated through mitosis within a specific cell lineage or neoplasm. ${ }^{35}$

The indications for and implications of gene-specific testing vs multiplex/panel testing are another testing issue. Following the discovery of BRCA1/2, it was apparent that these 2 genes were not responsible for all familial cases of breast and ovarian cancer. ${ }^{12}$ Hereditary cancer panel testing is designed to detect mutations in a menu of genes that might contribute to cancer risk and can identify a more robust population of women at increased risk of cancer. The disadvantages of panel testing include a higher rate of variances of unknown significance and findings of deleterious mutations in unexpected genes on a panel test. With the increasing number of cancer susceptibility genes identified, multiplex testing of many cancer susceptibility genes has become increasingly attractive as a cost- and time-efficient testing strategy.

If a hereditary syndrome is identified, the affected patient is faced with communicating the results and recommendations for cascade testing to her relatives. Cascade testing is genetic counseling and testing of blood relatives of individuals who have been identified with specific genetic mutations. Testing protocols and interventions may save lives and improve the health and quality of life for these family members. ${ }^{36}$ However, an obstacle to communicating results is a patient's potential lack of desire to inform relatives, secondary to the emotional burden of cancer or a guilty sentiment about possibly passing a mutation to her children. Therefore, a nonjudgmental environment and practical resources to help patients understand the meaning of a positive test are essential.

\section{Barriers to Genetic Testing}

Most women and their families are empowered by informative results of genetic testing. However, availability of health insurance coverage and other types of health care discrimination for those identified as mutation carriers are concerns. While legal protection against genetic discrimination is not complete, ${ }^{37}$ the following provisions afford some level of protection:

1. The Health Insurance Portability and Accountability Act (1996) specifically states that genetic information in the absence of a current diagnosis of illness does not constitute a preexisting condition. ${ }^{38}$

2. Executive Order 13145-To Prohibit Discrimination in Federal Employment Based on Genetic Information (February 2000) prohibits federal executive branch agencies from discriminating against applicants and employees on the basis of genetic information. ${ }^{39}$

3. The Genetic Information Nondiscrimination Act (May 2008) prohibits group health plans from denying coverage to a healthy individual or charging higher premiums based solely on a genetic predisposition to developing a disease in the future. ${ }^{40}$

Despite strong support from the United States Preventive Services Task Force and the NCCN, genetic testing rates remain low. Genetic testing is universally recommended for women with ovarian cancer, but the testing rates in this population are estimated to be $20 \%$ to $30 \% .{ }^{41,42}$ Multiple factors may contribute to low testing rates, including lack of physician awareness or time to fully assess family history, lack of patient acceptance, delays and/or denials by third-party payers, variable availability of genetic counseling professionals, lack of reimbursement for genetics professionals, racially and culturally disparate populations, and/or uninsured populations. ${ }^{43}$

Improvements in awareness of hereditary cancer, availability of genetics services, and communication of the importance of genetics evaluation can increase the rates of genetic testing. Strategies for increasing patient access to genetics services include telegenetics (telemedicine technology to provide clinical genetic services); group counseling 
sessions; integration or embedment of services within specialty oncology clinics; initial genetic testing performed by nongenetic clinicians; quality improvement initiatives; and other clinic support tools such as video education, computer-assisted family history collection, and patient navigation. ${ }^{44-46}$ Reducing financial barriers to genetic testing may improve access to services, especially among medically underserved, uninsured, or impoverished patients.

\section{CONCLUSION}

Many barriers to widespread genetic testing for patients and their families exist, but genetic testing of individuals who meet testing criteria is fundamental to oncologic care. Physicians, payers, and institutions must work collaboratively to maximize genetic testing with the goals of primary cancer prevention and treatment.

\section{ACKNOWLEDGMENTS}

The authors have no financial or proprietary interest in the subject matter of this article.

\section{REFERENCES}

1. The precision medicine initiative. Obama White House Archives. Accessed November 11, 2020. www.whitehouse.gov/precision-medicine

2. Collins FS, Varmus H. A new initiative on precision medicine. $N$ Engl J Med. 2015;372(9):793-795. doi: 10.1056/NEJMp1500523

3. Kaufman B, Shapira-Frommer R, Schmutzler RK, et al. Olaparib monotherapy in patients with advanced cancer and a germline. BRCA1/2 mutation. J Clin Oncol. 2015;33(3):244-250. doi: $10.1200 / J C O .2014 .56 .2728$

4. FDA approved olaparib (LYNPARZA, AstraZeneca Pharmaceuticals LP) for the maintenance treatment of adult patients with deleterious or suspected deleterious germline or somatic BRCA-mutated (gBRCAm or sBRCAm) advanced epithelial ovarian, fallopian tube or primary peritoneal cancer who are in complete or partial response to first-line platinum-based. U.S. Food and Drug Administration. Updated December 26, 2018. Accessed November 11, 2020. www.fda.gov/drugs/fda-approved-olaparib-lynparzaastrazeneca-pharmaceuticals-Ip-maintenance-treatmentadult-patients

5. Swisher EM, Lin KK, Oza AM, et al. Rucaparib in relapsed, platinum-sensitive high-grade ovarian carcinoma (ARIEL2 Part 1): an international, multicentre, open-label, phase 2 trial. Lancet Oncol. 2017;18(1):75-87. doi: 10.1016/S1470-2045(16)30559-9

6. FDA approves first cancer treatment for any solid tumor with a specific genetic feature. News release. U.S. Food and Drug Administration. May 23, 2017. Accessed November 11, 2020. www.fda.gov/news-events/press-announcements/fdaapproves-first-cancer-treatment-any-solid-tumor-specificgenetic-feature

7. Le DT, Uram JN, Wang H, et al. PD-1 blockade in tumors with mismatch-repair deficiency. $N$ Engl J Med. 2015;372(26):2509-2520. doi: 10.1056/NEJMoa1500596

8. Fader AN, Diaz LA, Armstrong DK, et al. Preliminary results of a phase II study: PD-1 blockade in mismatch repair-deficient, recurrent or persistent endometrial cancer. Abstract presented at: Society of Gynecologic Oncology 47th Annual Meeting on Women's Cancer; 2016; San Diego, CA.

9. Antoniou A, Pharoah PDP, Narod S, et al. Average risks of breast and ovarian cancer associated with BRCA1 or BRCA2 mutations detected in case series unselected for family history: a combined analysis of 22 studies. Am J Hum Genet. 2003;72(5):1117-1130. doi: 10.1086/375033

10. Pal T, Permuth-Wey J, Betts JA, et al. BRCA1 and BRCA2 mutations account for a large proportion of ovarian carcinoma cases. Cancer. 2005;104(12):2807-2816. doi: 10.1002/cncr.21536

11. Tung N, Lin NU, Kidd J, et al. Frequency of germline mutations in 25 cancer susceptibility genes in a sequential series of patients with breast cancer. $J$ Clin Oncol. 2016;34(13):1460-1468. doi: 10.1200/JCO.2015.65.0747

12. Pennington KP, Swisher EM. Hereditary ovarian cancer: beyond the usual suspects. Gynecol Oncol. 2012;124(2):347-353. doi: 10.1016/j.ygyno.2011.12.415

13. Walsh T, Casadei S, Lee MK, et al. Mutations in 12 genes for inherited ovarian, fallopian tube, and peritoneal carcinoma identified by massively parallel sequencing. Proc Natl Acad SciU S A. 2011;108(44):18032-18037. doi: 10.1073/pnas.1115052108

14. Norquist BM, Harrell MI, Brady MF, et al. Inherited mutations in women with ovarian carcinoma. JAMA Oncol. 2016;2(4):482-490. doi: 10.1001/jamaoncol.2015.5495

15. Lancaster JM, Powell CB, Chen LM, Richardson DL; SGO Clinical Practice Committee. Society of Gynecologic Oncology statement on risk assessment for inherited gynecologic cancer predispositions. Gynecol Oncol. 2015;136(1):3-7. doi: 10.1016/j.ygyno.2014.09.009

16. NCCN Guidelines ${ }^{\oplus}$. National Comprehensive Cancer Network. Accessed November 17, 2020. www.nccn.org/professionals/ physician_gls/default.aspx

17. Hermsen BBJ, Olivier RI, Verheijen RHM, et al. No efficacy of annual gynaecological screening in BRCA $1 / 2$ mutation carriers; an observational follow-up study. Br J Cancer. 2007;96(9):1335-1342. doi: 10.1038/sj.bjc.6603725

18. Barrow E, Hill J, Evans DG. Cancer risk in Lynch syndrome. Fam Cancer. 2013;12(2):229-240. doi: 10.1007/s10689-013-9615-1

19. Hendriks YMC, Wagner A, Morreau $\mathrm{H}$, et al. Cancer risk in hereditary nonpolyposis colorectal cancer due to MSH6 mutations: impact on counseling and surveillance. Gastroenterology. 2004;127(1):17-25. doi: $10.1053 /$ j.gastro.2004.03.068

20. Rijcken FEM, Mourits MJE, Kleibeuker JH, Hollema H, van der Zee AGJ. Gynecologic screening in hereditary nonpolyposis colorectal cancer. Gynecol Oncol. 2003;91(1):74-80. doi: 10.1016/s0090-8258(03)00371-8

21. Auranen A, Joutsiniemi T. A systematic review of gynecologic cancer surveillance in women belonging to hereditary nonpolyposis colorectal cancer (Lynch syndrome) families. Acta Obstet Gynecol Scand. 2011;90(5):437-444. doi: 10.1111/j.1600-0412.2011.01091.x

22. Pilarski R. Cowden syndrome: a critical review of the clinical literature. J Genet Couns. 2009;18(1):13-27. doi: 10.1007/s10897-008-9187-7

23. Starink TM, van der Veen JP, Arwet F, et al. The Cowden syndrome: a clinical and genetic study in 21 patients. Clin Genet. 1986;29(3):222-233. doi: 10.1111/j.1399-0004.1986.tb00816.x

24. Pilarski R, Stephens JA, Noss R, Fisher JL, Prior TW. Predicting PTEN mutations: an evaluation of Cowden syndrome and Bannayan-Riley-Ruvalcaba syndrome clinical features. J Med Genet. 2011;48(8):505-512. doi: 10.1136/jmg.2011.088807

25. Varga EA, Pastore $M$, Prior T, Herman GE, McBride KL. The prevalence of PTEN mutations in a clinical pediatric cohort with autism spectrum disorders, developmental delay, and macrocephaly. Genet Med. 2009;11(2):111-117. doi: 10.1097/GIM.0b013e31818fd762 
26. Pilarski R, Burt R, Kohlman W, Pho L, Shannon KM, Swisher E. Cowden syndrome and the PTEN hamartoma tumor syndrome: systematic review and revised diagnostic criteria. J Nat/ Cancer Inst. 2013;105(21):1607-1616. doi: 10.1093/jnci/djt277

27. Hearle N, Schumacher V, Menko FH, et al. Frequency and spectrum of cancers in Peutz-Jeghers syndrome. Clin Cancer Res. 2006;12(10):3209-3215. doi: 10.1158/1078-0432.CCR-06-0083

28. Hemminki A, Markie D, Tomlinson I, et al. A serine/threonine kinase gene defective in Peutz-Jeghers syndrome. Nature. 1998;391(6663):184-187. doi: 10.1038/34432

29. Chae HD, Jeon CH. Peutz-Jeghers syndrome with germline mutation of STK11. Ann Surg Treat Res. 2014;86(6):325-330. doi: 10.4174/astr.2014.86.6.325

30. Syngal S, Brand RE, Church JM, et al. ACG clinical guideline: genetic testing and management of hereditary gastrointestinal cancer syndromes. Am J Gastroenterol. 2015;110(2):223-262; quiz 263. doi: 10.1038/ajg.2014.435

31. Masciari S, Dewanwala A, Stoffel EM, et al. Gastric cancer in individuals with Li-Fraumeni syndrome. Genet Med. 2011;13(7):651-657. doi: 10.1097/GIM.0b013e31821628b6

32. Mai PL, Best AF, Peters JA, et al. Risks of first and subsequent cancers among TP53 mutation carriers in the National Cancer Institute Li-Fraumeni syndrome cohort. Cancer. 2016;122(23):3673-3681. doi: 10.1002/cncr.30248

33. Gonzalez KD, Noltner KA, Buzin $\mathrm{CH}$, et al. Beyond Li Fraumeni syndrome: clinical characteristics of families with p53 germline mutations. J Clin Oncol. 2009;27(8):1250-1256. doi: 10.1200/JCO.2008.16.6959

34. Li FP, Fraumeni JFJr, Mulvihill JJ, et al. A cancer family syndrome in twenty-four kindreds. Cancer Res. 1988;48(18):5358-5362.

35. Griffiths AJF, Miller JH, Suzuki DT, Lewontin RC, Gelbart WM. An Introduction to Genetic Analysis. 7th ed. W. H. Freeman; 2000.

36. Committee on Gynecologic Practice. ACOG committee opinion no. 727: cascade testing: testing women for known hereditary genetic mutations associated with cancer. Obstet Gynecol. 2018;131(1):e31-e34. doi: 10.1097/AOG.0000000000002457
37. Hall M, Rich SS. Laws restricting health insurers' use of genetic information: impact on genetic discrimination. Am J Hum Genet. 2000;66(1):293-307. doi: 10.1086/302714

38. Health information privacy. U.S. Department of Health \& Human Services. Accessed November 18, 2020. www.hhs. gov/hipaa/index.html

39. Executive order 13145-To prohibit discrimination in federal employment based on genetic information. Signed February 10, 2000. Accessed November 18, 2020. www.govinfo.gov/ content/pkg/FR-2000-02-10/pdf/00-3331.pdf

40. The Genetic Information Nondiscrimination Act of 2008; U.S. Equal Employment Opportunity Commission. Approved May 21, 2008. Accessed November 18, 2020. www.eeoc.gov/ statutes/genetic-information-nondiscrimination-act-2008

41. Wooster R, Bignell G, Lancaster J, et al. Identification of the breast cancer susceptibility gene BRCA2. Nature. 1995;378(6559):789-792. doi: 10.1038/378789a0

42. Lancaster JM, Wooster R, Mangion J, et al. BRCA2 mutations in primary breast and ovarian cancers. Nat Genet. 1996;13(2):238-240. doi: 10.1038/ng0696-238

43. Randall LM, Pothuri $B$, Swisher EM, et al. Multi-disciplinary summit on genetics for women with gynecologic cancers: a society of gynecologic oncology white paper. Gynecol Oncol. 2017;146(2):217-224. doi: 10.1016/j.ygyno.2017.06.002

44. Trepanier AM, Allain DC. Models of service delivery for cancer genetic risk assessment and counseling. J Genet Couns. 2014;23(2):239-253. doi: 10.1007/s10897-013-9655-6

45. Bednar EM, Oakley HD, Sun CC, et al. A universal genetic testing initiative for patients with high-grade, non-mucinous epithelial ovarian cancer and the implications for cancer treatment. Gynecol Oncol. 2017;146(2):399-404. doi: 10.1016/j.ygyno.2017.05.037

46. Manchanda R, Burnell M, Loggenberg K, et al. Cluster-randomised non-inferiority trial comparing DVD-assisted and traditional genetic counselling in systematic population testing for BRCA1/2 mutations. J Med Genet. 2016;53(7):472-480. doi: 10.1136/jmedgenet-2015-103740

\section{This article meets the Accreditation Council for Graduate Medical Education and the American Board of Medical Specialties Maintenance of Certification competencies for Patient Care and Medical Knowledge.}

C2020 by the author(s); licensee Ochsner Journal, Ochsner Clinic Foundation, New Orleans, LA. This article is an open access article distributed under the terms and conditions of the Creative Commons Attribution (CC BY) license (creativecommons.org/licenses/by/4.0/legalcode) that permits unrestricted use, distribution, and reproduction in any medium, provided the original author(s) and source are credited. 